Tjalling C. Koopmans Research Institute

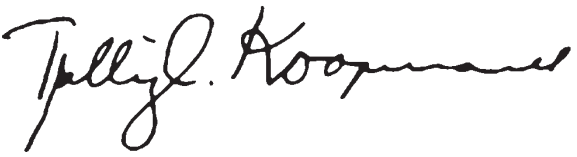

Discussion Paper Series nr: 05-14

\title{
RESERVE PRICES IN AUCTIONS AS REFERENCE POINTS
}

Stephanie Rosenkranz

Patrick W. Schmit 


\section{Tjalling C. Koopmans Research Institute Utrecht School of Economics \\ Utrecht University}

Vredenburg 138

3511 BG Utrecht

The Netherlands

telephone $\quad+31302539800$

fax $\quad+31302537373$

website www.koopmansinstitute.uu.nl

The Tjalling C. Koopmans Institute is the research institute and research school of Utrecht School of Economics.

It was founded in 2003, and named after Professor Tjalling C. Koopmans, Dutch-born Nobel Prize laureate in economics of 1975.

In the discussion papers series the Koopmans Institute publishes results of ongoing research for early dissemination of research results, and to enhance discussion with colleagues.

Please send any comments and suggestions on the Koopmans institute, or this series to M.Damhuis@econ.uu.nl

ontwerp voorblad: WR IK Utrecht

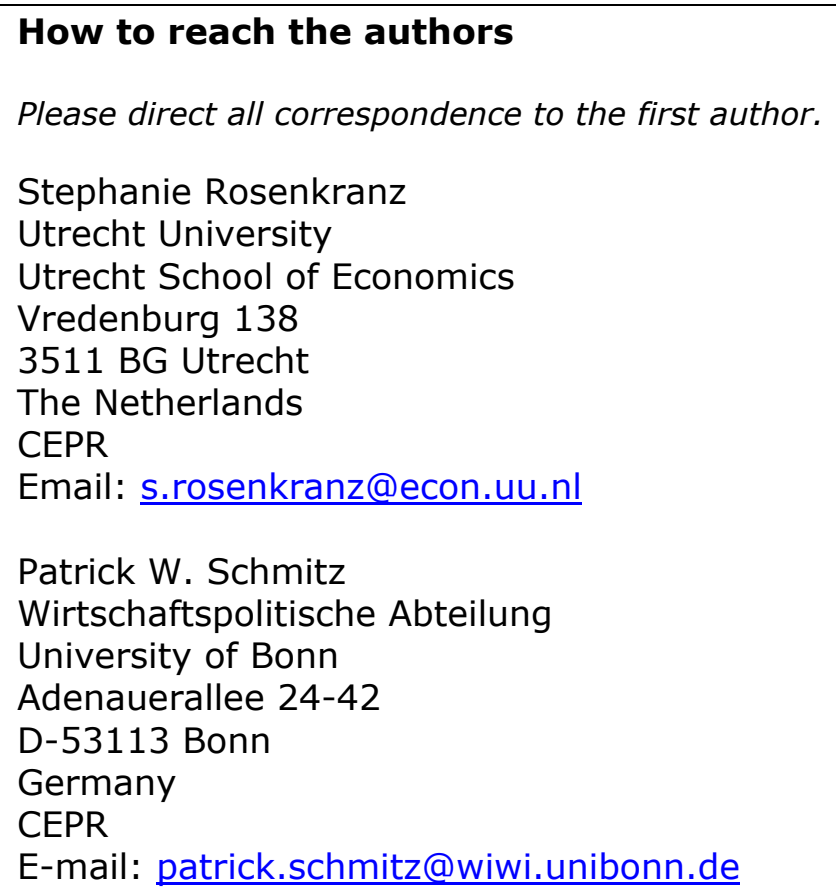


Utrecht School of Economics

Tjalling C. Koopmans Research Institute

Discussion Paper Series 05-14

\title{
RESERVE PRICES IN AUCTIONS AS REFERENCE POINTS
}

\author{
Stephanie Rosenkranz ${ }^{\mathrm{a}}$ \\ Patrick W. Schmit ${ }^{b}$ \\ aUtrecht School of Economics \\ Utrecht University \\ ${ }^{\mathrm{b}}$ Wirtschaftspolitische Abteilung \\ University of Bonn
}

April 2005

\begin{abstract}
We consider second-price and first-price auctions in the symmetric independent private values framework. We modify the standard model by the assumption that the bidders have reference-based utility, where the reserve price (minimum bid) plays the role of the reference point. In contrast to the usual result, the seller's optimal reserve price is increasing in the number of bidders. Even if an individual bidder perceives only a very small utility loss when he has to pay more than the reserve price, the impact on the optimal reserve price can be strong when there are many bidders..
\end{abstract}

Keywords: Auction theory; reference-dependent utility; reserve prices

JEL classification: D44; D81; D82

\section{Acknowledgements}

We would like to thank Urs Schweizer and Avner Shaked for helpful comments and suggestions. 


\section{Introduction}

In recent years, theorists have begun to use the standard tools of microeconomics to explore the implications of assumptions on human behavior based on insights imported from psychology. ${ }^{1}$ One of the most prominent departures from the standard economic paradigm is the assumption that people have reference-based utility; i.e., they assess utilities in comparison with reference points (see Kahneman and Tversky, 1979; Tversky and Kahneman, 1991). In this paper, we investigate how the analysis of the standard model of second-price and first-price auctions changes if the reserve price (minimum bid) announced by the seller plays the role of a reference point for the potential buyers.

We consider the well-known symmetric independent private values model, which is the simplest framework in which auctions have been analyzed. A remarkable result of the standard analysis is that the optimal reserve price does not depend on the number of bidders (see Myerson, 1981; Riley and Samuelson, 1981). In contrast, we will show that if there is a reference-point effect, then the optimal reserve price is increasing in the number of bidders.

Specifically, we assume that if a bidder wins the object and has to make a payment $t$, then his utility is given by $v-t-\varepsilon[t-r]$, where $v$ is the bidder's intrinsic valuation, $r$ is the reserve price, and $\varepsilon$ is a small positive number. The case $\varepsilon=0$ corresponds to the standard model in the auction literature. We are interested in the implications of the case $\varepsilon>0$, which captures the disutility that a buyer perceives if he has to pay more than the announced reserve price. $^{2}$

Note that in several ways our departure from the standard model is quite small. First, if $n=1$, there is no difference between our model and the standard model, because the buyer will not pay more than $r$. Second, if $n \geq 2$ and there is symmetric information, there is also no difference, because the seller will set $r$ equal to the largest valuation. Finally, if $n \geq 2$ and there is asymmetric information, the winning buyer's utility in our model can be different from the standard model, but the difference is small if $\varepsilon$ is small, which is the case that we have in mind. It will turn out that even if $\varepsilon$ is

\footnotetext{
${ }^{1}$ In a recent survey article, Rabin (2002) has called this new movement "second-wave behavioral economics," because it goes beyond simply pointing out problems with standard economic assumptions. For further references, see Tirole (2002), Camerer and Loewenstein (2003), and Fehr and Schmidt (2003).

${ }^{2}$ Note that by definition of a reserve price, $t$ is never smaller than $r$. In general, if a payment smaller than the reference price were possible, the utility from the associated gain would typically be smaller than the disutility from a same-sized loss, which is known as loss aversion (see Kahneman and Tversky, 1991).
} 
small, the reference point effect can have a significant impact on the seller's optimal reserve price if there are many bidders.

To the best of our knowledge, this is the first paper in the literature on auction theory in which the implications of a reserve price playing the role of a reference point are explored in a formal model. Empirically, the fact that reserve prices in auctions are indeed perceived by bidders as reference points has recently been shown in field studies as well as in laboratory experiments (see Häubl and Popkowski Leszczyc, 2003; Ariely and Simonson, 2003; Kamins, Drèze, and Folkes, 2004).

The remainder of the paper is organized as follows. In section 2 , the model is introduced and the equilibrium strategies in second-price and firstprice auctions are discussed. The main results are presented in section 3, where the seller's optimal reserve price is characterized. The results are further discussed in section 4 , followed by concluding remarks in section 5 . Some technical details have been relegated to the appendix.

\section{The model}

Consider a monopolistic seller who has a single, indivisible object for sale, that she cannot use herself. There are $n$ potential buyers. The seller conducts a (second-price or first-price) sealed-bid auction with reserve price $r$, which means that a bidder participating in the auction must at least bid $r$. If buyer $i$ does not win the auction, his utility is given by zero. If buyer $i$ wins the object and must pay the price $t_{i}$ according to the rules of the auction, then his utility is given by $v_{i}-t_{i}-\varepsilon\left[t_{i}-r\right]$. The case $\varepsilon=0$ is the usual case analyzed in the auction literature. A positive (but possibly very small) $\varepsilon$ captures the reference point effect as discussed in the introduction. Specifically, the buyer dislikes paying more than the reference point which is given by the reserve price $r$.

Buyer $i$ 's type $v_{i}$ is the realization of a random variable $\tilde{v}_{i}$. Each $\tilde{v}_{i}$ is independently and identically distributed on the interval $[0,1]$. The distribution function $F$ is strictly increasing and the differentiable density function is denoted by $f$. Moreover, we make the usual monotone hazard rate assumption, so that $\frac{1-F(v)}{f(v)}$ is increasing in $v .^{3}$ Only buyer $i$ knows his realized value $v_{i}$, while the other components of the model are assumed to be common knowledge. Each agent is interested in maximizing his or her expected payoff. Hence, our analysis is directly comparable with the standard model of the independent private values environment with symmetric bidders as

\footnotetext{
${ }^{3}$ Hence, we are in Myerson's (1981) "regular case".
} 
analyzed by Riley and Samuelson (1981). ${ }^{4}$

Second-price auction. In a second-price auction in which at least two bidders participate, the buyer submitting the highest bid wins the object, but he has to pay only the second-highest bid. ${ }^{5}$ If only one bidder participates, he wins and has to pay the reserve price $r$. It is well known that in the standard case $(\varepsilon=0)$, each buyer $i$ with $v_{i} \geq r$ will participate in the auction and bid his type $v_{i}$. In the present framework with $\varepsilon \geq 0$, this result can be generalized as follows.

Proposition 1 In a second-price auction, it is a weakly dominant strategy for a buyer of type $v$ to bid $b^{S}(v)=\frac{v+\varepsilon r}{1+\varepsilon}$ if $v \geq r$, and not to participate otherwise.

Proof. Since the price for the object will at least be $r$, it cannot be profitable for buyer $i$ to participate if $v_{i}<r$. Now consider a buyer $i$ with $v_{i} \geq r$. If buyer $i$ bids $b^{S}\left(v_{i}\right)$, he wins if $b^{S}\left(v_{i}\right)>t_{i}$, where $t_{i}$ is the maximum of the other bids if there are any, and $t_{i}=r$ otherwise. Consider a downward deviation to some $\tilde{b}<b^{S}\left(v_{i}\right)$. If $t_{i}<\tilde{b}<b^{S}\left(v_{i}\right)$, he still wins and pays $t_{i}$. If $\tilde{b}<b^{S}\left(v_{i}\right) \leq t_{i}$, his payoff is still zero. If $\tilde{b}<t_{i}<b^{S}\left(v_{i}\right)$, he now loses and gets zero, while he would have made a profit $v_{i}-t_{i}-\varepsilon\left[t_{i}-r\right]$ by bidding $b^{S}\left(v_{i}\right)$. This profit would have been positive, since $t_{i}<b^{S}\left(v_{i}\right)=\left(v_{i}+\varepsilon r\right) /(1+\varepsilon){ }^{6}$ Finally, a similar argument shows that an upward deviation $\tilde{b}>b^{S}\left(v_{i}\right)$ cannot be profitable.

The reference point effect implies that a buyer of type $v>r$ will bid strictly less than in the standard model (where $\varepsilon=0$ ). Now consider a buyer of type $v \geq r$. Let $G(v)=F(v)^{n-1}$ denote the probability that the values of all other buyers are smaller than $v$. The expected payment of the buyer can then be written as

$$
t^{S}(v)=r G(r)+\int_{r}^{v} \frac{w+\varepsilon r}{1+\varepsilon} d G(w) .
$$

In order to see this, note that he will only win if he has the highest value. He then must pay $r$ if all other buyers have types smaller than $r$, and he

\footnotetext{
${ }^{4}$ This model has been referred to as the "benchmark model" of auction theory in the survey article of McAfee and McMillan (1987). See also Matthews (1995), Krishna (2002), and Monteiro and Menezes (2004).

${ }^{5}$ For completeness, if there is more than one bidder with the highest bid, let the object go to each of them with equal probability. The same assumption can be made in the first-price auction. In any case, the probability of a tie will be zero.

${ }^{6}$ Given the tie-breaking rule of the previous footnote, if $\tilde{b}=t_{i}<b^{S}\left(v_{i}\right)$, he now loses this positive profit with probability $1 / 2$.
} 
must pay $b^{S}(w)=\frac{w+\varepsilon r}{1+\varepsilon}$ if $w \in(r, v)$ is the highest value of the other $n-1$ buyers.

First-price auction. In a first-price auction, the bidder with the highest bid wins and has to pay what he has bid. As is well known, the bidders do not have dominant strategies in a first-price auction. In the standard model $(\varepsilon=0)$, there is a symmetric equilibrium in which each bidder bids less than his true type. In the present framework, this result can be generalized, so that a bidder who participates in a first price auction bids $b^{F}(v)$, which is less than $b^{S}(v)$. More precisely, we get the following result.

Proposition 2 In a first-price auction, only buyers of type $v \geq r$ will participate. Their symmetric equilibrium bidding strategies are given by

$$
b^{F}(v)=\frac{1}{1+\varepsilon}\left(v+\varepsilon r-\int_{r}^{v} \frac{G(w)}{G(v)} d w\right) .
$$

Proof. It is obvious that buyer $i$ cannot benefit from participating if $v_{i}<r$. Now consider a buyer $i$ with $v_{i} \geq r$. Assume that all other buyers follow the strategy given in the proposition. Note that $b^{F}(v)$ is increasing. As a consequence, it is never profitable for buyer $i$ to bid more than $b^{F}(1)$, because then he would win for sure and could increase his payoff by slightly reducing his bid. Buyer $i$ thus considers to bid $b \in\left[r, b^{F}(1)\right]$. Note that there exists a value $z \in[r, 1]$ such that $b^{F}(z)=b$. Hence, buyer $i$ 's expected payoff from bidding $b$, which is given by $v_{i}-b-\varepsilon[b-r]$ times the probability that no other buyer bids more than $b$, can be written as follows:

$$
\begin{aligned}
& \left(v_{i}-b^{F}(z)-\varepsilon\left[b^{F}(z)-r\right]\right) G(z) \\
= & \left(v_{i}+\varepsilon r\right) G(z)-(z+\varepsilon r) G(z)+\int_{r}^{z} G(w) d w \\
= & \left(v_{i}-z\right) G(z)+\int_{r}^{z} G(w) d w
\end{aligned}
$$

If buyer $i$ bids $b^{F}\left(v_{i}\right)$, his expected payoff thus is $\int_{r}^{v_{i}} G(w) d w$. Since

$$
\begin{aligned}
& \left(v_{i}-z\right) G(z)+\int_{r}^{z} G(w) d w-\int_{r}^{v_{i}} G(w) d w \\
= & \int_{v_{i}}^{z}[G(w)-G(z)] d w \leq 0,
\end{aligned}
$$

it cannot be profitable for buyer $i$ to deviate from the strategy given in the proposition.

Now consider a buyer of type $v \geq r$. He pays $b^{F}(v)$ if all other buyers have types smaller than $v$, so his expected payment is

$$
t^{F}(v)=b^{F}(v) G(v)=\frac{1}{1+\varepsilon}\left((v+\varepsilon r) G(v)-\int_{r}^{v} G(w) d w\right) .
$$


It is easy to check (with partial integration) that $t^{F}(v)=t^{S}(v)$, which is in accordance with the well-known revenue equivalence principle. ${ }^{7}$ The winner only pays the second-highest bid in the second-price auction, but the equilibrium bids are lower in the first-price auction, so that the expected payment is the same in both cases.

\section{The optimal reserve price}

In order to characterize the optimal reserve price, let us now consider the seller's revenue. Recall that the seller does not know the buyers' types. Hence, the seller's expected revenue $\Pi(r)$ is simply $n$ times the expected value of the payment that a buyer makes to the seller (which is $t^{F}(v)$ if $v \geq r$, and 0 otherwise). Thus, with partial integration,

$$
\begin{aligned}
\Pi(r) & =\frac{n}{1+\varepsilon} \int_{r}^{1}\left((v+\varepsilon r) G(v)-\int_{r}^{v} G(w) d w\right) d F(v) \\
& =\frac{n}{1+\varepsilon} \int_{r}^{1}\left(v-\frac{1-F(v)}{f(v)}+\varepsilon r\right) F(v)^{n-1} d F(v) .
\end{aligned}
$$

Note that the seller will always set a strictly positive reserve price. This follows immediately from the fact that for $r=0$ the integrand is negative if $v$ is (close to) zero. Hence, increasing $r$ slightly above zero will unambiguously increase the expected profit. Moreover, note that if $\varepsilon=0$, then $\Pi(r)$ is obviously maximized by $r=r_{0}$, where $r_{0}-\frac{1-F\left(r_{0}\right)}{f\left(r_{0}\right)}=0$, so that the integrand is positive whenever $v \geq r_{0}$. The following proposition characterizes the optimal reserve price for $\varepsilon>0$.

Proposition 3 If $\varepsilon>0$, then the optimal reserve price $r^{*}$ is uniquely determined by the following equation:

$$
\frac{1}{\varepsilon}\left(r^{*}-\frac{1-F\left(r^{*}\right)}{f\left(r^{*}\right)}\right)=\frac{1-F\left(r^{*}\right)^{n}}{n F\left(r^{*}\right)^{n-1} f\left(r^{*}\right)}-r^{*}
$$

Proof. The first derivative of the seller's expected profit with respect to $r$ is

$$
\begin{aligned}
\frac{d \Pi(r)}{d r} & =\frac{n}{1+\varepsilon}\left(\int_{r}^{1} \varepsilon F(v)^{n-1} d F(v)-\left(r-\frac{1-F(r)}{f(r)}+\varepsilon r\right) F(r)^{n-1} f(r)\right) \\
& =\frac{1}{1+\varepsilon}\left(\varepsilon\left(1-F(r)^{n}\right)-\left(r-\frac{1-F(r)}{f(r)}+\varepsilon r\right) n F(r)^{n-1} f(r)\right) .
\end{aligned}
$$

\footnotetext{
${ }^{7}$ However, note that in our framework it is not straightforward to analyze entry fees or unusual formats such as all-pay auctions, where losing bidders must make payments. It is not obvious how the reference price should be adapted, and buyers might particularly dislike making payments when they do not get the object.
} 
Notice that $r^{*}>r_{0}$, since the first derivative of $\Pi(r)$ at $r=r_{0}$ is equal to $\frac{\varepsilon}{1+\varepsilon}\left[1-F\left(r_{0}\right)^{n}-\left(1-F\left(r_{0}\right)\right) n F\left(r_{0}\right)^{n-1}\right]$, which must be strictly positive since $F\left(r_{0}\right) \in(0,1)$. Given $\varepsilon>0$ and $n$, the first-order condition for the optimal reserve price $r^{*}$ can be written as $\alpha\left(r^{*}, \varepsilon\right)=\beta\left(r^{*}, n\right)$, where

$$
\begin{aligned}
\alpha(r, \varepsilon) & =\frac{1}{\varepsilon}\left(r-\frac{1-F(r)}{f(r)}\right), \\
\beta(r, n) & =\frac{1-F(r)^{n}}{n F(r)^{n-1} f(r)}-r .
\end{aligned}
$$

Note that given the monotone hazard rate assumption, there always exists a unique $r^{*}>0$, because when $r$ moves from zero to one, $\alpha(r, \varepsilon)$ increases from $-\frac{1}{\varepsilon f(0)}$ to $\frac{1}{\varepsilon}$, while the $\beta(r, n)$ decreases from $\infty$ to -1 (see the appendix), so that a straightforward intermediate value argument completes the proof.

What impact has the strength of the reference point effect, $\varepsilon$, on the optimal reserve price? Note that $\beta(r, n)$ does not vary with $\varepsilon$, and

$$
\frac{d}{d \varepsilon} \alpha(r, \varepsilon)=\frac{1}{\varepsilon^{2}}\left(\frac{1-F(r)}{f(r)}-r\right),
$$

which is positive if $r<r_{0}$ and negative if $r>r_{0}$. As is illustrated in Figure 1, this unambiguously implies that $r^{*}$ will increase if $\varepsilon$ is increased. Intuitively, a stronger reference point effect means that the buyers are less inclined to bid more than $r$, so that the seller will set a higher reserve price.

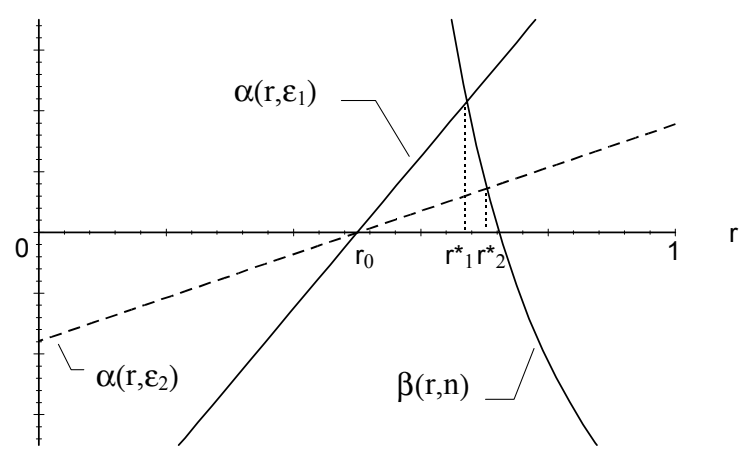

Figure 1. If $\varepsilon$ is increased from $\varepsilon_{1}$ to $\varepsilon_{2}$, the optimal reserve price increases from $r_{1}^{*}$ to $r_{2}^{*}$.

Next, consider the impact of the number of potential buyers, $n$, on the optimal reserve price. Notice that $\alpha(r, \varepsilon)$ does not depend on $n$ and it is easy to verify that

$$
\frac{d}{d n} \beta(r, n)=-\frac{1-F(r)^{n}+n \ln F(r)}{n^{2} F(r)^{n-1} f(r)}>0,
$$


where the inequality follows from the fact that $1-x+\ln x<0$ for $x \in(0,1)$. Thus, if $n$ is increased, the optimal reserve price $r^{*}$ will increase (see Figure 2 ). Intuitively, the more bidders there are, the higher is the expected value of the highest type. Hence, a given reserve price will less likely lead to the no trade outcome, so that increasing the reserve price in order to weaken the reduction of the buyers' bids due to the reference point effect becomes more attractive.

The comparative statics findings are summarized in the following result.

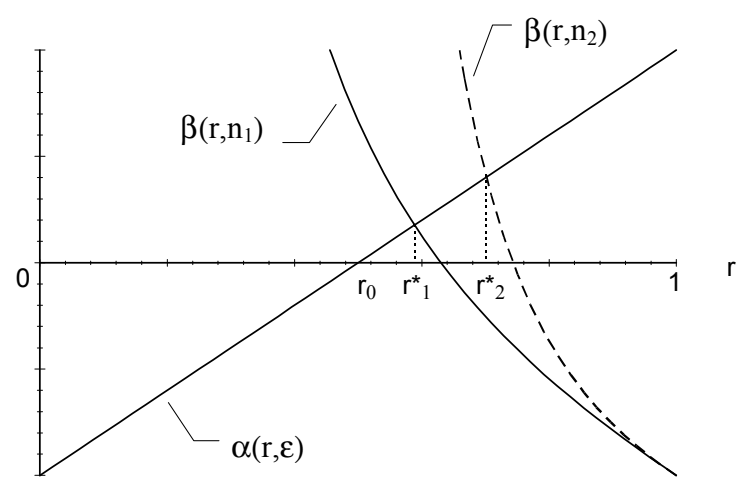

Figure 2. If $n$ is increased from $n_{1}$ to $n_{2}$, the optimal reserve price increases from $r_{1}^{*}$ to $r_{2}^{*}$.

Proposition 4 (a) The optimal reserve price is increasing in the strength of the reference point effect, $\varepsilon$.

(b) The optimal reserve price is increasing in the number of bidders, $n$.

Proof. This follows immediately from the preceding discussion.

Note that result (b) is in stark contrast to the standard result, which says that the optimal reserve price $r_{0}$ is independent of the number of bidders. ${ }^{8}$ It should be emphasized that even if $\varepsilon$ is very small, the impact of the reference point effect on the optimal reserve price $r^{*}$ can be significant if the number of potential buyers is sufficiently large. For example, consider the uniform distribution, so that $r_{0}=0.5$. Assume that $\varepsilon=0.01$; i.e., the reference point effect is quite small. As a result, the optimal reserve price for $n=2$ is only slightly increased to $r^{*} \approx 0.501$, but for $n=20$ it is significantly increased to $r^{*} \approx 0.76$.

\footnotetext{
${ }^{8}$ Notice that our model could be re-interpreted as a modification of the standard model, where the winner must pay $t_{i}+\varepsilon\left[t_{i}-r\right]$ instead of $t_{i}$. If the payment $\varepsilon\left[t_{i}-r\right]$ accrued to the seller, revenue equivalence between our modified auction and the standard auction would imply that $r$ is independent of $n$. However, in our framework $\varepsilon\left[t_{i}-r\right]$ is a loss, so that the seller's incentives are different.
} 


\section{Discussion}

Strong reference point effect. Even though we think that small values of $\varepsilon$ are most plausible, in order to better understand the results it is interesting to note what happens if $\varepsilon$ becomes large. In this case, the buyers are basically unwilling to pay more than the reserve price. Hence, if $\varepsilon$ is increased, the optimal reserve price converges to the optimal price posted by a profitmaximizing seller who cannot use an auction. Such a seller will set a price $p$ in order to maximize her expected profit $p\left[1-F(p)^{n}\right]$, which is the price times the probability that there is at least one buyer willing to pay the price. The first-order condition is $1-F\left(p^{*}\right)^{n}-p^{*} n F\left(p^{*}\right)^{n-1} f\left(p^{*}\right)=0$. Inspection of (1) immediately reveals that $r^{*}$ converges to $p^{*}$ when $\varepsilon$ goes to infinity.

The value of additional bidders. In the standard auction model with $\varepsilon=0$, Bulow and Klemperer (1996) have shown that the expected profit of a seller who sets an optimal reserve price in the presence of $n$ potential buyers is smaller than the expected profit of a seller who sets $r=0$ when there are $n+1$ potential buyers. Hence, even if $n$ is large, the marginal value of one additional bidder is greater than the benefit of setting an optimal reserve price. This striking result is no longer true if there is a reference point effect $(\varepsilon>0)$, given that the number of bidders is sufficiently large. In order to see this, note that (with partial integration)

$$
\begin{aligned}
\Pi(0) & =\frac{n}{1+\varepsilon} \int_{0}^{1}(v f(v)-[1-F(v)]) F(v)^{n-1} d v \\
& =\frac{n}{1+\varepsilon} \int_{0}^{1} v[1-F(v)](n-1) F(v)^{n-2} f(v) d v \\
& =\frac{1}{1+\varepsilon} E\left[\tilde{v}_{(2)}\right],
\end{aligned}
$$

where $\tilde{v}_{(2)}$ is the second highest element of $\left\{\tilde{v}_{1}, \ldots, \tilde{v}_{n}\right\} \cdot{ }^{9}$ Notice that $\Pi(0)$ is increasing in $n$ and it converges to $\frac{1}{1+\varepsilon}<1$ if $n$ goes to infinity, for any given $\varepsilon>0$. It is straightforward to see that $\Pi\left(r^{*}\right)$ must increase in $n$ and converge to 1 (this would even be the case if the seller could only post a price). Hence, if $n$ is sufficiently large, the value of an additional buyer will be smaller than the benefit from setting the optimal reserve price.

Of course, if the number of potential buyers is small, the finding of Bulow and Klemperer (1996) is valid, provided that the reference point effect is sufficiently small. For example, consider the uniform distribution. The expected profit with the optimal reserve price and $n=2$ is then smaller than the expected profit with $r=0$ and $n=3$ if $\varepsilon<\hat{\varepsilon}$, with $\hat{\varepsilon} \approx 0.22$.

\footnotetext{
${ }^{9}$ Thus, the distribution function of $\tilde{v}_{(2)}$ is $\operatorname{Pr}\left\{\tilde{v}_{(2)} \leq v\right\}=F(v)^{n}+n F(v)^{n-1}(1-F(v))$, and the density function is $n(n-1) F(v)^{n-2} f(v)(1-F(v))$.
} 
A generalized model. So far, it has been assumed that the seller's only interest in the object is to maximize the expected revenue from sale. Let us now consider what happens if it is known that the seller attaches a value $v_{S} \in[0,1]$ to the object. In this case, one might argue that $v_{S}$ is another candidate that could be adopted by the buyers as reference point. ${ }^{10}$ Therefore, let us assume now that the reference price is $\rho=\lambda r+(1-\lambda) v_{S}$, where $\lambda \in[0,1]$; i.e., it is a linear combination of the reserve price $r$ and the seller's value $v_{S}{ }^{11}$ Hence, if a buyer of type $v$ wins the object and has to make payment $t$, his payoff is now given by $v-t-\varepsilon[t-\rho]$.

It is straightforward to modify the analysis of the basic model to obtain the following results. A buyer of type $v$ now participates if $v \geq \bar{v}(r)=$ $(1+\varepsilon) r-\varepsilon \rho$. The equilibrium bidding functions are given by $\bar{b}^{S}(v)=\frac{v+\varepsilon \rho}{1+\varepsilon}$ in the second-price auction and $\bar{b}^{F}(v)=\frac{1}{1+\varepsilon}\left(v+\varepsilon \rho-\int_{\bar{v}(r)}^{v} \frac{G(w)}{G(v)} d v\right)$ in the first-price auction. Since the seller derives a value $v_{S}$ from the object if it is left unsold, which happens with probability $F(\bar{v}(r))^{n}$, her expected payoff can be written as

$$
\begin{aligned}
\bar{\Pi}(r) & =\frac{n}{1+\varepsilon} \int_{\bar{v}(r)}^{1}\left(v-\frac{1-F(v)}{f(v)}+\varepsilon \rho\right) F(v)^{n-1} d F(v)+F(\bar{v}(r))^{n} v_{S} \\
& =\frac{n}{1+\varepsilon} \int_{\bar{v}(r)}^{1}\left(v-\frac{1-F(v)}{f(v)}+\varepsilon \lambda\left[r-v_{S}\right]-v_{S}\right) F(v)^{n-1} d F(v)+v_{S} .
\end{aligned}
$$

If $\varepsilon=0$, the optimal reserve price is now implicitly defined by $\bar{r}_{0}-\frac{1-F\left(\bar{r}_{0}\right)}{f\left(\bar{r}_{0}\right)}=$ $v_{S}$. If $\varepsilon>0$, it is straightforward to check that the optimal reserve price $\bar{r}^{*}$ is given by $\bar{r}^{*}=\frac{\bar{v}^{*}+(1-\lambda) \varepsilon v_{S}}{1+(1-\lambda) \varepsilon}$, where

$$
\frac{1}{\varepsilon}\left(\bar{v}^{*}-\frac{1-F\left(\bar{v}^{*}\right)}{f\left(\bar{v}^{*}\right)}-v_{S}\right)=\lambda \frac{1-F\left(\bar{v}^{*}\right)^{n}}{n F\left(\bar{v}^{*}\right)^{n-1} f\left(\bar{v}^{*}\right)}+(1-\lambda) \frac{1-F\left(\bar{v}^{*}\right)}{f\left(\bar{v}^{*}\right)}-\bar{v}^{*}+v_{S} .
$$

By inspection of this first-order condition, we can make the following observations. If the reference point is only identified with the seller's value $(\lambda=0)$, then the optimal reserve price is independent of the number of bidders. In this case we get $\left(\bar{v}^{*}=\bar{r}_{0}\right.$ and hence) $v_{S}<\bar{r}^{*}<\bar{r}_{0}$, and $\bar{r}^{*}$ is decreasing in $\varepsilon$. Intuitively, the larger is $\varepsilon$, the less willing are the buyers to pay more than $v_{S}$. However, if $\lambda=1$, we find again that $\bar{r}^{*}>\bar{r}_{0}$ and that $\left(\bar{v}^{*}\right.$ and hence) $\bar{r}^{*}$ is increasing in $\varepsilon$, as in the basic model. For intermediate values of $\lambda$, the optimal reserve price need not be monotone in $\varepsilon$, although it will converge to $v_{S}$ when $\varepsilon$ goes to infinity. More importantly, if $\lambda \in(0,1]$,

\footnotetext{
${ }^{10}$ In their empirical study, Häubl and Popkowski Leszczyc (2003) have pointed out that the reserve price as a seller-specified reference point remains to be relevant, even if other reference prices are available.

${ }^{11}$ Notice that it cannot be in the interest of the seller to set $r$ smaller than $v_{S}$, thus we always have $\rho \leq r$.
} 
then the optimal reserve price is again increasing in the number of bidders. In other words, our main finding holds whenever the reserve price has at least some (possibly very small) influence on what the buyers perceive as a cognitive reference price.

\section{Concluding remarks}

We have shown that prominent results of the by now standard private independent values model of auctions with symmetric bidders are not robust when the bidders' utilities are influenced by a (possibly very small) reference point effect. Our analysis suggests that sellers might increase their expected payoffs if they set higher reserve prices than standard theory prescribes, ${ }^{12}$ and that optimal reserve prices may well be increasing in the number of bidders. ${ }^{13}$ It could be an interesting avenue for future research to further incorporate insights from behavioral economics into auction theory. For instance, the starting price of a Dutch auction might be another candidate for a reference point and might hence influence the seller's expected profit in a way not predicted by traditional analysis. ${ }^{14}$ In sequential auctions, the price obtained in period $t$ might play the role of a reference point in period $t+1$. The endowment effect, according to which ownership of an object appears to increase one's valuation, might have an interesting impact on auction models with resale opportunities. ${ }^{15}$ Thus, exploring the implications of departures from standard economic paradigms seems to be an exciting task for auction theorists.

\footnotetext{
${ }^{12}$ Note that increasing the reserve price has also been suggested in the literature on bidding rings, see Graham and Marshall (1987) and Mailath and Zemsky (1991).

${ }^{13}$ Lucking-Reiley (2000) reports results from a field experiment suggesting that the optimal reserve price may indeed be increasing in the number of bidders. He points out that more experiments are needed, which we also consider to be desirable in the light of the theory that we have proposed.

${ }^{14}$ More generally, the reference price might be adapted during the oral bidding process in an open auction format.

${ }^{15}$ For instance, Zheng (2002) has shown that the optimal allocation derived by Myerson (1981) can under certain circumstances also be achieved when the bidders cannot commit not to resell. Yet, this requires resale to take place, which is less probable to happen if there is an endowment effect. But if the endowment effect is sufficiently strong, we are again in the world of Myerson (1981). Hence, small endowment effects might be the most damaging ones from the seller's viewpoint.
} 


\section{Appendix}

In order to show that $\beta(r, n)$ is decreasing in $r$, note that

$$
\begin{aligned}
\frac{d}{d r}\left(\frac{1-F(r)^{n}}{F(r)^{n-1} f(r)}\right)= & \frac{1}{\left[F(r)^{n-1} f(r)\right]^{2}}\left[-n F(r)^{2 n-2} f(r)^{2}\right. \\
& \left.-\left(1-F(r)^{n}\right)\left((n-1) F(r)^{n-2} f(r)^{2}+F(r)^{n-1} f^{\prime}(r)\right)\right] .
\end{aligned}
$$

It is claimed that this expression is negative for all $r \in(0,1)$. In order to see that this is indeed the case, multiply with

$$
\left[F(r)^{n-1} f(r)\right]^{2} \frac{1-F(r)}{\left[1-F(r)^{n}\right] F(r)^{n-1}}>0,
$$

so that we must show

$$
\left(-\frac{n F(r)^{n-1}(1-F(r))}{1-F(r)^{n}}-(n-1) \frac{1-F(r)}{F(r)}\right) f(r)^{2}-(1-F(r)) f^{\prime}(r)<0 .
$$

Since $f^{2}(r)+(1-F(r)) f^{\prime}(r)>0$ due to the monotone hazard rate assumption, the left-hand side is smaller than

$$
\begin{aligned}
& \left(-\frac{n F(r)^{n-1}(1-F(r))}{1-F(r)^{n}}-(n-1) \frac{1-F(r)}{F(r)}+1\right) f(r)^{2} \\
= & \frac{(1-F(r))\left(-n F(r)^{n}-(n-1)\left(1-F(r)^{n}\right)\right)+\left(1-F(r)^{n}\right) F(r)}{\left(1-F(r)^{n}\right) F(r)} f(r)^{2} \\
= & {\left[1-F(r)^{n}-n(1-F(r))\right] \frac{f(r)^{2}}{\left(1-F(r)^{n}\right) F(r)} \leq 0 }
\end{aligned}
$$

where the inequality follows since the term in square brackets is always smaller than $1-F(1)^{n}-n(1-F(1))=0$. 


\section{References}

Ariely, D. and I. Simonson (2003), Buying, bidding, playing, or competing? Value assessment and decision dynamics in online auctions, Journal of Consumer Psychology 13, 113-132.

Bulow, J. and P. Klemperer (1996), Auctions versus negotiations, American Economic Review 86, 180-194.

Camerer, C.F. and G. Loewenstein (2003), Behavioral economics: Past, present, future. In: Camerer, C.F., G. Loewenstein, and M. Rabin (Eds.), Advances in Behavioral Economics, Princeton University Press.

Fehr, E. and K.M. Schmidt (2003), Theories of fairness and reciprocity evidence and economic applications. In: Dewatripont, M., L. Hansen, and S. Turnovsky (Eds.), Advances in Economics and Econometrics, Eighth World Congress of the Econometric Society, Vol. 1, Cambridge: Cambridge University Press, 208-257.

Graham, D.A. and R.C. Marshall (1987), Collusive bidder behavior at single-object second-price and English auctions, Journal of Political Economy 95, 1217-1239.

Häubl, G. and P.T.L. Popkowski Leszczyc (2003), Minimum prices and product valuations in auctions. Working paper.

Kahneman, D. and A. Tversky (1979), Prospect theory: An analysis of decision under risk, Econometrica 47, 263-291.

Kamins, M.A., X. Drèze, and V.S. Folkes (2004), Effects of seller-supplied prices on buyers' product evaluations: Reference prices in an internet auction context, Journal of Consumer Research, forthcoming.

Krishna, V. (2002), Auction Theory, Academic Press.

Lucking-Reiley, D. (2000), Field experiments on the effects of reserve prices in auctions: More magic on the internet. Working Paper.

Mailath, G.J. and P. Zemsky (1991), Collusion in second price auctions with heterogeneous bidders, Games and Economic Behavior 3, 467486.

Matthews, S.A. (1995), A Technical Primer on Auction Theory I: Independent Private Values, Discussion Paper No. 1096, Northwestern University. 
McAfee, R.P. and J. McMillan (1987), Auctions and bidding, Journal of Economic Literature 25, 699-738.

Monteiro, P.K. and F.M. Menezes (2004), An Introduction to Auction Theory. Forthcoming.

Myerson, R.B. (1981), Optimal auction design, Mathematics of Operations Research 6, 58-73.

Rabin, M. (2002), A perspective on psychology and economics, European Economic Review 46, 657-685.

Riley, J.G. and W.F. Samuelson (1981), Optimal auctions, American Economic Review 71, 381-392.

Tirole, J. (2002), Rational irrationality: Some economics of self-management, European Economic Review 46, 633-655.

Tversky, A. and D. Kahneman (1991), Loss aversion in riskless choice: A reference-dependent model, Quarterly Journal of Economics 106, $1039-1061$.

Zheng, C.Z. (2002), Optimal auction with resale, Econometrica 70, 21972224 . 